\title{
Molecular Cloning of Rat Obese cDNA and Augmented Gene Expression in Genetically Obese Zucker Fatty (fa/fa) Rats
}

\author{
Yoshihiro Ogawa, Hiroaki Masuzaki, Naohi Isse, Taku Okazaki, Kiyoshi Mori, Michika Shigemoto, Noriko Satoh, \\ Naohisa Tamura, Kiminori Hosoda, Yasunao Yoshimasa, Hisato Jingami, Teruo Kawada, * and Kazuwa Nakao \\ Department of Medicine and Clinical Science, Kyoto University Graduate School of Medicine, Kyoto 606, Japan; and *Department of \\ Food Science and Technology, Faculty of Agriculture, Kyoto University, Kyoto 606, Japan
}

\begin{abstract}
The obese $(o b)$ gene has recently been isolated through a positional cloning approach, the mutation of which causes a marked hereditary obesity and diabetes mellitus in mice. In the present study, we isolated rat $o b$ cDNA and examined the tissue distribution of the $o b$ gene expression in rats. We also studied the gene expression in genetically obese Zucker fatty $(f a / f a)$ rats. The rat $o b$ gene product, a 167 amino acid protein with a putative signal sequence, was 96 and $83 \%$ homologous to the mouse and human ob proteins, respectively. Northern blot analysis using the rat $o b$ cDNA probe identified a single mRNA species of $4.5 \mathrm{~kb}$ in size in the adipose tissue, while no significant amount of $o b$ mRNA was present in other tissues in rats. The ob gene was expressed in the adipose tissue with region specificities. The rank order of the ob mRNA level in the adipose tissue was epididymal, retroperitoneal, and pericardial white adipose tissue $>$ mesenteric and subcutaneous white adipose tissue $\geq$ interscapular brown adipose tissue. The $o b$ gene expression occurred in mature adipocytes rather than in stromalvascular cells isolated from the rat adipose tissue. Expression of the $o b$ gene was markedly augmented in all the adipose tissue examined in Zucker fatty $(f a / f a)$ rats at the stage of established obesity. The present study leads to the better understanding of the physiologic and pathophysiologic roles of the ob gene. (J. Clin. Invest. 1995. 96:1647-1652.) Key words: adipocyte $\bullet$ brown adipose tissue $\bullet$ obesity $\bullet$ stromalvascular cell $\cdot$ white adipose tissue
\end{abstract}

\section{Introduction}

Obesity is a disorder characterized by increased mass of adipose tissue that results from a systemic imbalance between food intake and energy expenditure (1). The condition is often asso-

Address correspondence to Yoshihiro Ogawa, Department of Medicine and Clinical Science, Kyoto University Graduate School of Medicine, 54 Shogoin Kawahara-cho, Sakyo-ku, Kyoto 606, Japan. Phone: 81-75751-3173; FAX: 81-75-771-9452.

Received for publication 4 April 1995 and accepted in revised form 30 May 1995.

J. Clin. Invest.

(C) The American Society for Clinical Investigation, Inc.

0021-9738/95/09/1647/06\$2.00

Volume 96, September 1995, 1647-1652 ciated with a variety of cardiovascular and metabolic disorders such as hypertension, hyperglycemia, and hyperlipidemia, and constitutes one of the most important medical and health problems.

The crucial discovery of the obese $(o b)^{1}$ gene by Friedman and colleagues has provided new insight into the molecular mechanisms underlying obesity (2). They isolated the $o b$ gene by positional genetics, which, when mutated, results in a marked hereditary obesity and non-insulin-dependent diabetes mellitus in mice. The $o b$ gene encodes a 167 amino acid polypeptide with the structural features of a secreted protein and expression of the $o b$ gene is abundant in and specific to the white adipose tissue (WAT) in mice.

A large number of experimental rat models of obesity have been widely used to study the pathogenesis, therapy, and prevention of obesity (3). However, molecular cloning of $o b$ cDNA has been reported only in mice and humans, and expression of the $o b$ gene has been examined only in mice (2). In the present study we isolated rat $o b$ cDNA and examined the tissue distribution of the $o b$ gene expression in rats. We also studied the gene expression in mature adipocytes obtained from the rat adipose tissue. To further explore the physiologic and pathophysiologic implication of the $o b$ gene in the development of obesity, we examined the gene expression in genetically obese Zucker fatty $(f a / f a)$ rats.

\section{Methods}

Preparation of a rat ob cDNA probe. A 404-bp fragment of rat $o b$ cDNA was prepared by the reverse transcription-PCR (RT-PCR). Using a DNA synthesizer (model 381A; Applied Biosystems Inc., Foster City, CA), two oligonucleotide primers (5'-CCTATCCAGAAAGTCCAGGA-3', and 5'-ATGTCCTGCAGAGAGCCCTG-3') were synthesized, which are complementary to $(-)$ and $(+)$ strands of the mouse $o b$ cDNA sequences, respectively (2). First-stranded cDNA was synthesized from $10 \mu \mathrm{g}$ of total RNA from the rat epididymal fat pad by the oligo (dT)-primed reverse transcription (Superscript ${ }^{\text {; }}$;ibco, Grand Island, NY), and subjected to the PCR (4). The reaction profile was as follows; denaturation at $94^{\circ} \mathrm{C}$ for $1 \mathrm{~min}$, annealing at $55^{\circ} \mathrm{C}$ for $1 \mathrm{~min}$, and extension at $72^{\circ} \mathrm{C}$ for $2 \mathrm{~min}$, for 30 cycles. The PCR product of the predicted size was further isolated and subcloned into pGEM-T vector (Promega Corp. Madison, WI) for sequencing. The rat $o b$ cDNA fragment thus obtained had $96 \%$ nucleotide sequence homology to the corresponding mouse $o b$ cDNA sequences (2).

1. Abbreviations used in this paper: 5'-RACE, rapid amplification of 5 '-cDNA ends; BAT, brown adipose tissue; fa, fatty; ob, obese; RTPCR, reverse transcription-PCR; WAT, white adipose tissue. 
Table I. Profiles of 12-wk-old Male Zucker Fatty ( fa/fa) Rats and Their Lean Littermates

\begin{tabular}{|c|c|c|c|c|c|c|c|c|}
\hline & \multicolumn{4}{|c|}{ Lean } & \multicolumn{4}{|c|}{ Fatty } \\
\hline & L1 & L2 & L3 & Mean \pm SD & F1 & F2 & F3 & Mean \pm SD \\
\hline Body weight (grams) & 264 & 250 & 225 & $246 \pm 20$ & 380 & 375 & 355 & $370 \pm 13 *$ \\
\hline Glucose (mg/dl) & 151 & 139 & 160 & $150 \pm 10$ & 189 & 204 & 228 & $207 \pm 20 *$ \\
\hline Total cholesterol (mg/dl) & 68 & 68 & 55 & $64 \pm 8$ & 133 & 111 & 120 & $121 \pm 11^{*}$ \\
\hline Triglyceride (mg/dl) & 72 & 76 & 68 & $72 \pm 4$ & 177 & 161 & 153 & $164 \pm 12 *$ \\
\hline Insulin $(\mu \mathrm{U} / \mathrm{ml})$ & 17.8 & 24.0 & 13.7 & $18.5 \pm 5.2$ & 120.0 & 89.1 & 82.1 & $97.1 \pm 20.1^{*}$ \\
\hline
\end{tabular}

$\mathrm{F} 1, \mathrm{~F} 2$, and $\mathrm{F} 3$ represent three male Wistar fatty $(f a / f a)$ rats, while $\mathrm{L} 1, \mathrm{~L} 2$, and $\mathrm{L} 3$ represent their lean littermates. $* P<0.01$ vs the lean littermates.

Library screening. A Sprague-Dawley rat fat cell cDNA library in $\lambda$ gt11 vector (Clontech Inc., Mountain View, $C A$ ) was screened with the ${ }^{32}$ P-labeled rat $o b$ cDNA fragment. Prehybridization and hybridization were carried out as described $(5,6)$. The filters were washed in 2 $\times \operatorname{SSC}(1 \times \operatorname{SSC}$ is $0.15 \mathrm{M} \mathrm{NaCl}, 0.015 \mathrm{M} \mathrm{Na}$ citrate $)$ and $0.1 \%$ SDS twice at $60^{\circ} \mathrm{C}$, and in $0.2 \times \mathrm{SSC}$ and $0.1 \%$ SDS three times at $60^{\circ} \mathrm{C}$. Approximately $4 \times 10^{5}$ plaques were screened, and 4 positive signals (2A, 3A, 3B, and 4B) were obtained (Fig. 1 A). The 2-kb, 3-kb, 521$\mathrm{bp}$, and 1-kb EcoRI fragments from the positive clones were subcloned into pBluescript vector (Stratagene Inc., La Jolla, CA) for further analysis.

Rapid amplification of $5^{\prime}-c D N A$ ends $\left(5^{\prime}-R A C E\right)$. To determine the 5 '-extended sequences of rat $o b$ cDNA fragment, the 5'-RACE was performed using the 5'-AmpliFINDER RACE kit (Clontech Inc.). Approximately $20 \mu \mathrm{g}$ of total RNA from the rat epididymal fat pad was reverse transcribed by a rat $o b$ cDNA specific antisense primer ( $5^{\prime}-$ CTGTTGATAGACTGCCAG-3'). The single-stranded cDNA was ligated to the AmpliFINDER anchor, and amplified by the PCR as recommended by the manufacturer, using the AmpliFINDER anchor primer and a second upstream rat $o b$ cDNA specific antisense primer (5'ATCCTGGTGACAATGGTC-3'). A single fragment of $\sim 230$ bp in size was obtained, which was subcloned into pGEM-T vector for sequencing. To exclude the nucleotide misincorporation during the PCR amplification, a total of 10 clones were sequenced, all of which proved to be identical (data not shown).

Amplification of Zucker fatty ( $f a / f a)$ rat ob cDNA. Based upon the nucleotide sequences of the cloned rat $o b$ cDNA (Fig. $1 B$ ), two oligonucleotide primers (5'-GACCCCAGCGAGGAAAAT-3', and 5'AGCCCGGTGGTCT-TGGAAA-3') were synthesized to amplify by the RT-PCR method as described above the full-length Zucker fatty ( $f a / f a$ ) rat $o b$ cDNA coding region. The RT-PCR product thus obtained was subjected to the direct sequencing.

DNA sequencing. Sequence determination was carried out by the dideoxy chain termination method (7) using Sequenase version 2.0 (U.S. Biochemical Corp., Cleveland, $\mathrm{OH}$ ). Direct sequencing of the RT-PCR products was performed using PRISM sequenase fluorescent dye-labeled dideoxynucleotide kit (Applied Biosystems Inc.). All DNA sequences were confirmed by reading both DNA strands.

Animals. Male Sprague-Dawley rats at $10 \mathrm{wk}$ of age were used to study the tissue distribution of the $o b$ gene expression in rats. The gene expression was also examined in 12-wk-old male Zucker fatty ( $f a / f a$ ) rats and their male lean littermates (Shimizu Experimental Supplies, Kyoto, Japan). These animals were housed in a temperature-, humidity-, and light-controlled room and allowed free access to water and standard rat chow (CE-2, $352 \mathrm{kcal} / 100$ grams; CLEA Japan, Tokyo, Japan). A $0.2-\mathrm{ml}$ blood was sampled from the tail vein, and plasma glucose, total cholesterol, triglyceride, and insulin levels were measured. Table I summarizes brief profiles of 12-wk-old male Zucker fatty ( $\mathrm{fa}$ / $f a$ ) rats and their male lean littermates used in the present study. By 12 wk of age, Zucker fatty ( $f a / f a$ ) rats developed marked obesity with hyperglycemia, hyperlipidemia, and hyperinsulinemia.
Tissue preparation. After rats were anesthetized by ether inhalation, the adipose tissue and other tissues were removed immediately from rats. The white adipose tissue (WAT) was obtained from the epididymal, mesenteric, subcutaneous abdominal, retroperitoneal, and pericardial fat pads, while the brown adipose tissue (BAT) was from the interscapular fat pad. All the other tissues were carefully dissected to prevent the contamination of the adipose tissue. Tissues were frozen in liquid nitrogen, and stored at $-70^{\circ} \mathrm{C}$ until use.

Isolation of mature adipocytes and stromal-vascular cells. The mature adipocytes and stromal-vascular cells were prepared according to the method of Hauner et al. (8) with slight modifications. In brief, the adipose tissue from 7-wk-old Sprague-Dawley rats was rinsed immediately in Hanks' balanced salt solution (Gibco), and fibrous tissues and blood vessels were carefully dissected and removed. The remaining tissue was digested by $1 \mathrm{mg} / \mathrm{ml}$ collagenase (Type I, Sigma Chemical Co., St. Louis, MO) for $30-45 \mathrm{~min}$ at $37^{\circ} \mathrm{C}$ under continuous shaking $(150 \mathrm{rpm})$. The dispersed tissue was filtered through a nylon mesh with a pore size of $250 \mu \mathrm{m}$ and centrifuged, thereby giving rise to the floating mature adipocytes and the sedimented stromal-vascular cells.

Total RNA extraction and Northern blot analysis. Total RNA was extracted from rat tissues, and mature adipocytes and stromal-vascular cells by the method of Chomczynski and Sacchi (9). Northern blot analysis was performed as described $(5,6)$ using the ${ }^{32} \mathrm{P}$-labeled rat $o b$ cDNA fragment as a probe. A human $\beta$-actin genomic probe (Wako Pure Chemical Inc., Ltd., Osaka, Japan) was used to monitor the amount of total RNA in each sample. Actin transcripts were roughly equivalent among different RNA samples (data not shown). Autoradiographs were quantitated by densitometric scanning. The rat $o b$ mRNA levels were normalized to the $\beta$-actin mRNA level in the adipose tissue from Zucker fatty $(f a / f a)$ rats and their lean littermates to correct for differences in the amount of RNA applied. The $o b$ mRNA levels (arbitrary units) were expressed relative to that of the epididymal WAT from Zucker lean rats (The $o b$ mRNA level in $10 \mu \mathrm{g}$ of total RNA from the epididymal WAT is defined as $100 \mathrm{U}$ ).

\section{Results}

Molecular cloning of rat ob cDNA. Approximately $4 \times 10^{5}$ plaques were screened from a rat fat cell cDNA library and 4 primary positives were obtained. Nucleotide sequence analysis revealed that all the positive clones contain the overlapping nucleotide sequences highly homologous to the mouse $o b$ cDNA sequences (2). The 5 '-ends of all the cDNA clones (2A, 3A, 3B, and 4B), however, were located $90 \mathrm{bp}, 309 \mathrm{bp}, 110$ $\mathrm{bp}$, and $13 \mathrm{bp}$ downstream of the ATG start codon, respectively (Fig. $1 A$ ). To obtain the $5^{\prime}$-extended sequences of rat $o b$ cDNA fragment, we performed the 5'-RACE experiment. The 5'RACE product of $232 \mathrm{bp}$ in size contained nucleotide sequences 
(A)

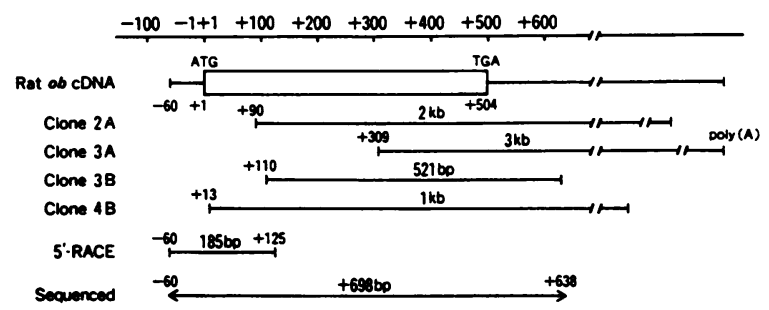

(B)
GGAGGAATCCCTGCTCCAGCAGCTGCAAGgTCCAAGAAGAAGAAGACCCCAGCG AGGAAAATGTGCTGGAGACCCCTGTGCCGGTTCCTGTGGCTTTGGTCCTATCTG
ME TCYSTRPAT OP OLLUCY TCCTATGTTCAAGCTGTGCCTATCCACAAAGTCCAGGATGACACCAAMACCCTC +

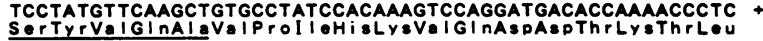
ATCAAGACCATTGTCACCAGGATCAATGACATTTCACACACGCAGTCGGTATCC + 16 M GCCAGGCAGAGGGTCACCGGTTTGGACTTCATTCCCGGGCTTCACCCCATTCTG +2 AGTTTGTCCAAGATGGACCAGACCCTGGCAGTCTATCAACAGATCCTCACCAGC t? AGTTTGTCCAAGATGGACCAGACCCTGGCAGTCTATCAACAGATCCTCACCAGC
SOIL USE TTGCCTTCCCAAAACGTGCTGCAGATAGCTCATGACCTGGAGACCTGCGAGA + 18 CTCTTCATCTGCTGG

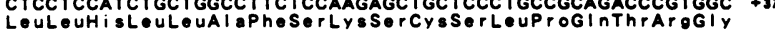
CTGCAGAAGCCAGAGAGCCTGGATGGCGTCCTGGAAGCCTCGCTCTACTCCACA + 20 GAGGTGGTGGCTCTGAGCAGGCTGCAGGGCTCTCTGCAGGACATTCTTCAACAG
GIUVOIVIAI
+ TTGGACCTTAGCCCTGAATGCTGAAGTTTCCAAGACCACCGGGTCCCGAGGAT + $\mathbf{3 9}$

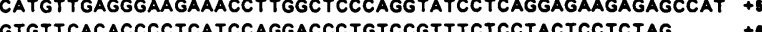

Figure 1. (A) Characterization of rat $o b$ cDNA clones $(2 A, 3 A, 3 B$, and $4 B)$ and the $5^{\prime}-\mathrm{RACE}$ product $\left(5^{\prime}-\mathrm{RACE}\right)$. The coding region is indicated by an open box. The nucleotide sequence is numbered, with +1 referring to the ATG translation start codon. $(B)$ Nucleotide and deduced amino acid sequences of rat $o b$ cDNA. The translation stop codon is indicated by $* * *$. The putative signal sequence is underlined. These sequence data are available from GenBank under accession number D45862.

60 bp upstream to the ATG start codon (Fig. $1 A$ ). The overlapping nucleotide sequences between all the cDNA clones and the 5'-RACE product were identical and sequences of the 60bp 5 '-untranslated region and the first 12-bp coding region were deduced from the $5^{\prime}$-RACE product.

Fig. $1 B$ shows the nucleotide and deduced amino acid sequences of the full-length rat $o b$ cDNA. The nucleotide sequence from +67 to +470 was identical to that of the rat $o b$ cDNA probe obtained by the PCR. The rat $o b$ cDNA coding region was 96 and $83 \%$ identical to the mouse and human $o b$ cDNA coding regions, respectively $(2,10)$. The Zucker fatty $(f a / f a)$ rat $o b$ cDNA coding region was identical to that of Sprague-Dawley rats (data not shown). Analysis of the deduced amino acid sequences revealed that the rat ob protein comprises 167 amino acids (Fig. 2). The $\mathbf{N H}_{2}$-terminal hydrophobic 21 amino acid peptide represented the signal sequence. The amino acid sequence of the rat ob protein was 96 and $83 \%$ homologous to those of the mouse and human ob proteins (2), respectively.

Adipose tissue-specific expression of the ob gene in rats. Northern blot analysis using the rat $o b$ cDNA probe identified a single mRNA species of $4.5 \mathrm{~kb}$ in size in the adipose tissue, while no significant amount of $o b$ mRNA was detected in the brain, heart, lung, stomach, liver, spleen, pancreas, small intestine, kidney, testis, and skeletal muscle in 10-wk-old male Sprague-Dawley rats (Fig. $3 A$ ).

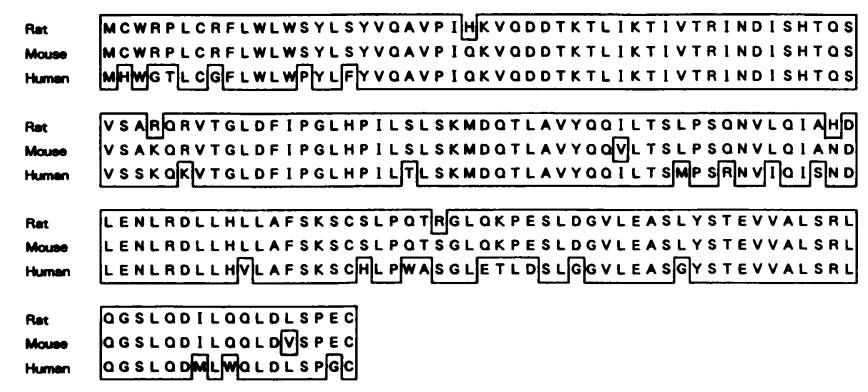

Figure 2. Alignment of the rat, mouse, and human ob proteins. Amino acid sequences are shown in one-letter code. Identical amino acids are boxed.

Regional distribution of the ob gene expression in the rat adipose tissue. To elucidate the regional distribution of the $o b$ gene expression in the adipose tissue, we studied the gene expression in the adipose tissue obtained from the epididymal, mesenteric, subcutaneous, retroperitoneal, pericardial, and interscapular fat pads in 10-wk-old male Sprague-Dawley rats (Fig. $3 \mathrm{~B}$ ). The $o b$ gene was expressed abundantly in all the WAT with region specificities. Expression of the $o b$ gene was also detected in the interscapular BAT. The rank order of the $o b$ mRNA level in the adipose tissue was epididymal, retroperitoneal, and pericardial WAT $>$ mesenteric and subcutaneous WAT $\geq$ interscapular BAT.

Adipocyte-specific expression of the ob gene in rats. To determine the cellular localization of the $o b$ gene expression in the adipose tissue, we examined the gene expression in mature adipocytes and stromal-vascular cells obtained from the rat adipose tissue. The $o b$ gene was expressed abundantly in mature adipocytes, while no appreciable amount of $o b$ mRNA was present in stromal-vascular cells (Fig. 4). The $o b$ mRNA level in mature adipocytes was higher than that in the adipose tissue, from which the adipocytes were obtained, indicating the enrichment of $o b$ mRNA in mature adipocytes.

Augmented expression of the ob gene in Zucker fatty ( $\mathrm{fa}$ / fa) rats. To further explore the physiologic and pathophysiologic roles of the $o b$ gene in the development of obesity, we examined the gene expression in the adipose tissue from genetically obese Zucker fatty $(f a / f a)$ rats at the stage of established obesity. The adipose tissue from Zucker fatty $(f a / f a)$ rats and their lean littermates also contained a single mRNA species of the same size of $o b$ mRNA in Sprague-Dawley rats (Fig. $5 A$ ). The $o b$ mRNA levels were very similar in the adipose tissue derived from the same region using the same rat strains (data not shown). The $o b$ mRNA levels in the adipose tissue from Zucker lean rats were comparable to those from Sprague-Dawley rats. The rank order of the $o b$ mRNA level in the adipose tissue from Zucker lean rats was retroperitoneal WAT $>$ subcutaneous WAT $\geq$ epididymal and mesenteric WAT $>$ interscapular BAT > pericardial WAT (Fig. 5 B).

Expression of the $o b$ gene was markedly augmented in all the adipose tissue examined in Zucker fatty $(f a / f a)$ rats, and the gene expression was also up-regulated in a region-specific manner (Fig. $5 A$ ). In Zucker fatty ( $f a / f a)$ rats, the augmentation of the $o b$ gene expression was $\sim 12-, 6-, 6-, 2-, 86-$, and 22-fold as compared with their lean littermates in the epididymal, mesenteric, subcutaneous, retroperitoneal, and pericardial WAT, and in the interscapular BAT, respectively (Fig. 5 B). 
(A)

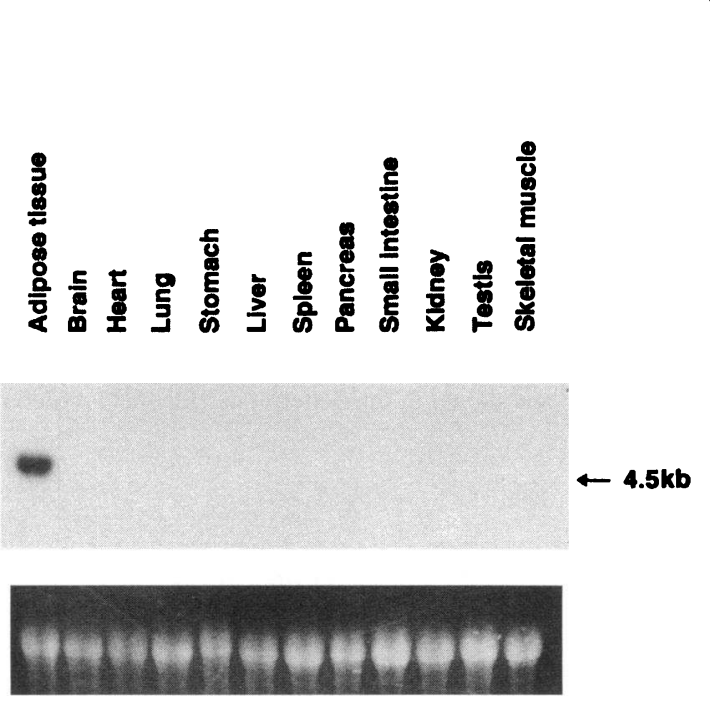

The rank order of the $o b$ mRNA level in the adipose tissue from Zucker fatty $(f a / f a)$ rats was, therefore, epididymal WAT $\geq$ retroperitoneal and subcutaneous WAT $>$ pericardial and mesenteric WAT, and interscapular BAT.

\section{Discussion}

In the present study, we succeeded in the isolation and sequence determination of rat $o b$ cDNA. Nucleotide and deduced amino acid sequence analysis revealed that the rat ob protein is a 167 amino acid polypeptide with a putative signal sequence.

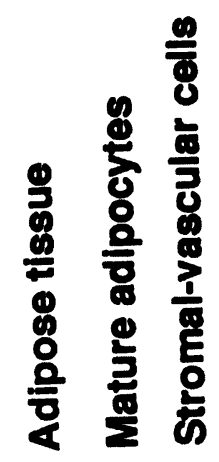

ob

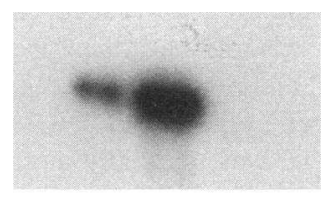

285

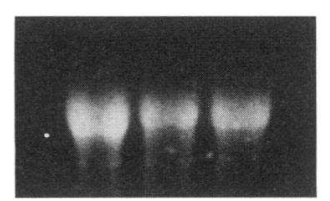

(B)

WAT BAT

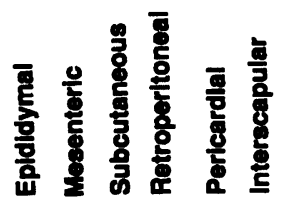

ob

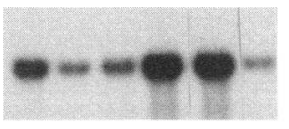

285

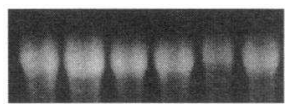

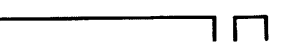

Figure 3. ( A ) Northern blot analysis of rat $o b$ mRNA in 10-wk-old male Sprague-Dawley rats $(n$ $=4)$. A representative case is shown. Total RNA (10 $\mu \mathrm{g} /$ lane) from various rat tissues was analyzed. The $28 \mathrm{~S}$ ribosomal RNA bands visualized with ethidium bromide are shown in the bottom panel. ( $B$ ) Northern blot analysis of rat $o b$ mRNA in the adipose tissue from the epididymal, mesenteric, subcutaneous, retroperitoneal, and pericardial fat pads in 10-wk-old male Sprague-Dawley rats $(n=4)$. A representative case is shown. Total RNA $(10 \mu \mathrm{g} /$ lane) was analyzed. The $28 \mathrm{~S}$ ribosomal RNA bands visualized with ethidium bromide are shown in the bottom panel.
Although two variant cDNAs for the 166 and 167 amino acid ob proteins have been found in mice and humans (2), we could not obtain the cDNA clones for the 166 amino acid rat ob protein during the cDNA library screening. The structure of the rat ob protein elucidated in the present study was highly homologous to those of the mouse and human ob proteins (2). These observations indicate that the structure of the ob protein is evolutionarily conserved among species.

The present study demonstrates that the $o b$ gene is expressed abundantly and specifically in the adipose tissue in rats. These results are consistent with the adipose tissue-specific expression of the $o b$ gene in mice and humans $(2,10)$. The present study also represents the first demonstration of the regional differences in the $o b$ gene expression in the WAT from rats. Recently, we have observed that the $o b$ gene expression occurs in the WAT with region-specificities in mice and humans (10, Shigemoto et al., unpublished observations). The physiologic significance of the regional differences in the $o b$ gene expression in the WAT must await further investigation.

The adipose tissue is composed of various cell types; mature adipocytes, various blood cells, endothelial cells, pericytes, and adipose precursor cells $(11,12)$. To determine the cellular localization of the $o b$ gene expression in the adipose tissue, we examined the gene expression in mature adipocytes and stromal-vascular cells. The present study provides the first direct evidence that the $o b$ gene expression is restricted to mature adipocytes in the adipose tissue. It has been demonstrated that stromal-vascular cells contain a significant amount of adipose precursor cells which are able to differentiate into mature adipocytes $(8,11,12)$. These observations indicate that adipose precursor cells express no appreciable amount of $o b$ mRNA and suggest that the $o b$ gene expression is induced during the adipose cell differentiation and/or maturation. Further studies are needed to elucidate the mechanisms by which the $o b$ gene expression is regulated in the adipocytes.

In the present study, the $o b$ gene expression was markedly augmented in the WAT from Zucker fatty $(f a / f a)$ rats. It has also been demonstrated that the $o b$ gene expression is augmented in the WAT from C57BL/6J $o b / o b$ mice (2). Nonsense mutation of the $o b$ gene in C57BL/6J $o b / o b$ mice (2) appar- 

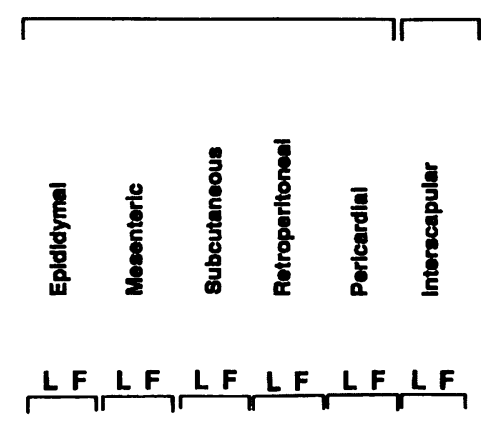

Ob MRNA

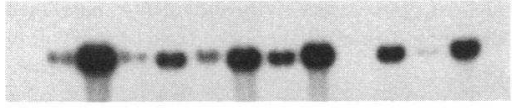

285

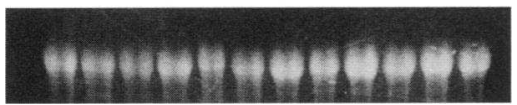

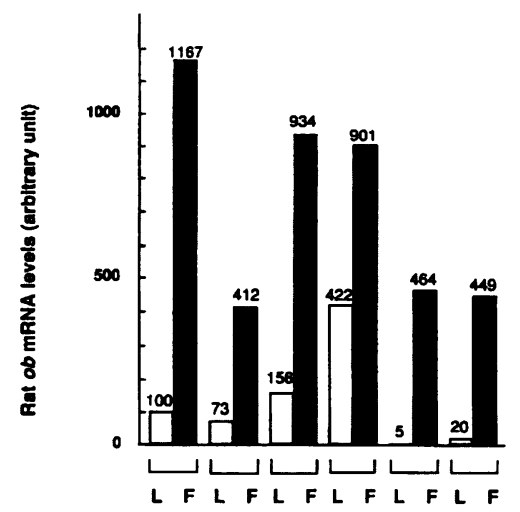

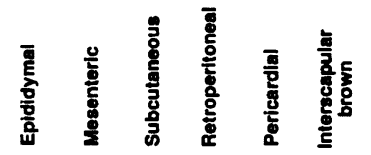

Figure 5. (A) Northern blot analysis of rat $o b$ mRNA in the adipose tissue from 12-wk-old male Zucker fatty $(\mathrm{fa} / \mathrm{fa})$ rats and their male lean littermates $(n=3)$. A representative case is shown. The $28 \mathrm{~S}$ ribosomal RNA bands visualized with ethidium bromide are shown in the bottom panel. $(L)$ Zucker lean rats; $(F)$ Zucker fatty $(f a / f a)$ rats. $(B)$ The rat $o b$ mRNA levels in the adipose tissue from 12-wk-old male Zucker fatty $(f a / f a)$ rats and their male lean littermates. The mean mRNA levels in Zucker fatty $(f a / f a)$ rats and their lean littermates $(n=3)$ are indicated by closed and open boxes, respectively. $(L)$ Zucker lean rats; $(F)$ Zucker fatty $(f a / f a)$ rats. ently encodes an inactive ob protein, thereby augmenting the $o b$ gene expression. On the other hand, in the present study, no mutations were observed in the full-length $o b$ cDNA coding region of Zucker fatty $(f a / f a)$ rats. The rat gene fatty $(f a)$ has been shown to be a homologue of the mouse gene diabetes $(d b)$ (13). Furthermore, parabiosis experiments have suggested that both $f a / f a$ rats and $d b / d b$ mice are resistant to the effects of the circulating satiety factor (possibly the ob protein) (14, 15 ). The defect in the action of the ob protein may make its synthesis up-regulated in Zucker fatty ( $f a / f a$ ) rats. We have recently observed that the $o b$ gene expression is markedly augmented not only in genetically obese C57BL/6J $o b / o b$ mice and Zucker fatty $(\mathrm{fa} / \mathrm{fa}$ ) rats but in a model of acquired obesity (cafeteria-fed rats) (Masuzaki et al., unpublished observations). These findings indicate that the $o b$ gene expression is upregulated in the adipose tissue even without genetic alteration. Accordingly, augmented expression of the $o b$ gene observed in $\mathrm{C} 57 \mathrm{BL} / 6 \mathrm{~J} o b / o b$ mice and Zucker fatty $(\mathrm{fa} / \mathrm{fa}$ ) rats may be due not only to the defective interaction between the ob protein and its putative receptor but also to the obese phenotype per se.

There are several adipose tissue-specific genes that are activated during the development of obesity (11). The lipoprotein lipase (LPL) gene, for instance, is expressed abundantly in the adipose tissue, and the gene expression is also augmented in all the WAT from both Zucker fatty $(f a / f a)$ rats and cafeteriafed rats (16, Masuzaki et al., unpublished observations). It has been demonstrated that insulin and other hormones increase the LPL gene expression in isolated rat adipocytes (17). Augmented expression of the $o b$ gene in Zucker fatty $(f a / f a)$ rats, therefore, might also be due to the action of insulin, the plasma concentrations of which were elevated in these animals (Table I). Further studies are ongoing in our laboratory to elucidate the hormonal regulation of the $o b$ gene expression both in vitro and in vivo.

In Zucker fatty ( $f a / f a$ ) rats, expression of the $o b$ gene was markedly augmented in all the WAT with region specificities. These results are consistent with our unpublished observations that the augmentation of the $o b$ gene expression is region specific in the adipose tissue from C57BL/6J $o b / o b$ mice (Shigemoto et al., unpublished observations). Further studies are needed to elucidate the significance of the differential regulation of the $o b$ gene expression in the WAT in the development of obesity.

In the present study, expression of the $o b$ gene was also detected in the interscapular BAT in rats, and the gene expression was markedly augmented in the BAT from Zucker fatty ( $f a / f a)$ rats as compared with their lean littermates. These results suggest the presence of obesity-linked regulation of the $o b$ gene expression in the BAT as well as in the WAT. Further studies are necessary to elucidate the physiologic and pathophysiologic significance of the $o b$ gene in the BAT.

In conclusion, we succeeded in the isolation and sequence determination of rat $o b$ cDNA and elucidated the adipocytespecific expression of the $o b$ gene in rats. The present study demonstrates that the $o b$ gene expression occurs in the adipose tissue with region specificities in rats and that the gene expression is markedly up-regulated in all the adipose tissue from genetically obese Zucker fatty $(f a / f a)$ rats. The present study. will facilitate the better understanding of the physiologic and pathophysiologic implication of the $o b$ gene.

\section{Acknowledgments}

We thank Ms. Y. Horiuchi for her technical assistance. We also acknowledge Ms. C. Kawahara, Ms. M. Kawakatsu, and Ms. S. Sakabe for their secretarial assistance.

This work was supported in part by research grants from the Japanese Ministry of Education, Science and Culture; the Japanese Ministry of Health and Welfare; Yamanouchi Foundation for Research on Metabolic Disorders; the Salt Science Research Foundation; and Japan Diabetes Foundation.

\section{References}

1. Weigle, D. S. 1994. Appetite and the regulation of body composition. FASEB J. 8:302-310.

2. Zhang, Y., R. Proenca, M. Maffei, M. Barone, L. Leopold, and J. M. 
Friedman. 1994. Positional cloning of the mouse obese gene and its human homologue. Nature (Lond.). 372:425-432.

3. Johnson, P. R., M. R. C. Greenwood, B. A. Horwitz, and J. S. Stern. 1991. Animal models of obesity: genetic aspects. Annu. Rev. Nutr. 11:325-353.

4. Saiki, R. K., D. H. Gelfand, S. Stoffel, S. J. Scharf, R. Higuchi, G. T. Horn, K. B. Mullis, and H. A. Erlich. 1988. Primer-directed enzymatic amplification of DNA with a thermostable DNA polymerase. Science (Wash. DC). 239:487-491.

5. Ogawa, Y., H. Itoh, N. Tamura, S. Suga, T. Yoshimasa, M. Uehira, S. Matsuda, S. Shiono, H. Nishimoto, and K. Nakao. 1994. Molecular cloning of the complementary DNA and gene that encode mouse brain natriuretic peptide and generation of transgenic mice that overexpress the brain natriuretic peptide gene. J. Clin. Invest. 93:1911-1921.

6. Tamura, N., Y. Ogawa, H. Itoh, H. Arai, S. Suga, O. Nakagawa, Y. Komatsu, I. Kishimoto, K. Takaya, T. Yoshimasa, S. Shiono, and K. Nakao. 1994 Molecular cloning of hamster brain and atrial natriuretic peptides: cardiomyopathic hamsters are useful animal models for brain and atrial natriuretic peptides. J. Clin. Invest. 94:1059-1068.

7. Sanger, F., S. Nicklen, and A. R. Coulson. 1977. DNA sequencing with chain-terminating inhibitors. Proc. Natl. Acad. Sci. USA. 74:5463-5469.

8. Hauner, H., G. Entenmann, M. Wabitsch, D. Gaillard, G. Ailhaud, R Negrel, and F. Pfeiffer. 1989. Promoting effects of glucocorticoids on the differentiation of human adipocyte precursor cells cultured in a chemically defined medium. J. Clin. Invest. 84:1663-1670.

9. Chomczynski, N., and N. Sacchi. 1987. Single-step method of RNA isolation by acid guanidinium thiocyanate-phenol-chloroform extraction. Anal. Biochem. 162:156-159.
10. Masuzaki, H., Y. Ogawa, N. Isse, N. Satoh, T. Okazaki, M. Shigemoto, K. Mori, N. Tamura, K. Hosoda, Y. Yoshimasa, et al. 1995. Human obese gene expression: adipocyte-specific expression and regional differences in the adipose tissue. Diabetes. 44:855-858.

11. Ailhaud, G., P. Grimaldi, and R. Negrel. 1992. Cellular and molecular aspects of adipose tissue development. Annu. Rev. Nutr. 12:207-233.

12. Deslex, S., R. Negrel, and G. Ailhaud. 1987. Development of a chemically defined serum-free medium for differentiation of rat adipose precursor cells. Exp. Cell Res. 168:15-30.

13. Truett, G. E., N. Bahary, J. M. Friedman, and R. L. Leibel. 1991. Rat obesity gene fatty $(f a)$ maps to chromosome 5 : evidence for homology with the mouse gene diabetes (db). Proc. Natl. Acad. Sci. USA. 88:7806-7809.

14. Coleman, D. L. 1973. Effects of parabiosis of obese with diabetes and normal mice. Diabetologia. 9:294-298.

15. Harris, R. B. S., E. Hervey, G. R. Hervey, and G. Tobin. 1987. Body composition of lean and obese Zucker rats in parabiosis. Int. J. Obes. 11:275283.

16. Shimomura, I., K. Tokunaga, S. Jiao, T. Funahashi, Y. Keno, T. Kobatake, K. Kotani, H. Suzuki, T. Yamamoto, S. Tarui, and Y. Masuzawa. 1992. Marked enhancement of acyl-CoA synthetase activity and mRNA, paralleled to lipoprotein lipase mRNA, in adipose tissues of Zucker obese rats ( $\mathrm{fa} / \mathrm{fa}$ ). Biochim. Biophys. Acta. 1124:112-118.

17. Ong, J. M., T. G. Kirchgessner, M. C. Schotz, and P. A. Kern. 1988 Insulin increases the synthetic rate and messenger RNA level of lipoprotein lipase in isolated rat adipocytes. J. Biol. Chem. 263:12933-12938. 